\title{
O Enfermeiro na Unidade de Saúde da Família: Estudo Socioclínico Institucional
}

\author{
The Nurse at the Family Health Unit: Institutional Socioclinical Study \\ La enfermera de la Unidad de Salud de la Familia:Estudio Socioclínico Institucional \\ Adicéa de Souza Ferreira1, Ana Lúcia Abrahão
}

Como citar esse artigo. Ferreira, AS;

Abrahão, AL. O Enfermeiro na Unidade de Saúde da Família: Estudo Socioclínico Institucional. Revista Pró-UniverSUS. 2019 Jul/Dez.; 10 (2): 83-85.

\begin{abstract}
Resumo
Objetivos: Conhecer o processo de trabalho de enfermeiros atuantes nas Unidades de Saúde da Família localizadas em um município da Região Serrana do Estado do Rio de Janeiro; identificar os fatores que intervém na implementação de ações gerencias voltada para o cuidado. Método: Estudo de abordagem qualitativa com emprego do desenho Socioclínico Institucional, que opera na lógica de transformar a realidade investigada para compreender a pesquisa. Utiliza-se da produção coletiva do conhecimento e troca de saberes e aprenderes entre participantes e pesquisadores. Resultados esperados: Espera-se contribuir com o processo de trabalho dos enfermeiros atuantes nas Unidades de Saúde quanto a gerência do cuidado.

Palavras-chave: Análise institucional, Cuidados de Enfermagem, Estratégia Saúde da Família, Gestão em Saúde.
\end{abstract}

\begin{abstract}
Objectives: To know the work process of nurses working in Family Health Units located in a municipality in the highland region of Rio de Janeiro State; identify the factors that intervene in the implementation of management actions focused on care. Method: Study of qualitative approach using the Institutional Socioclinical Design, which operates in the logic of transforming the reality investigated to understand the research. It uses the collective production of knowledge and exchange of knowledge and learning between participants and researchers. Expected Results: It is expected to contribute to the work process of nurses working in Health Units regarding care management.
\end{abstract}

Keywords: Institutional analysis Nursing Care, Family Health Strategy, Health Management.

\section{Resumen}

Objetivos: conocer el proceso de trabajo de las enfermeras que trabajan en las unidades de salud familiar ubicadas en un municipio de la región montañosa del estado de Río de Janeiro; Identificar los factores que intervienen en la implementación de acciones de gestión centradas en la atención. Método: Estudio del enfoque cualitativo utilizando el Diseño Socioclínico Institucional, que opera en la lógica de transformar la realidad investigada para comprender la investigación. Utiliza la producción colectiva de conocimiento y el intercambio de conocimiento y aprendizaje entre participantes e investigadores. Resultados esperados: se espera que contribuya al proceso de trabajo de las enfermeras que trabajan en las unidades de salud con respecto a la gestión de la atención

Palabras clave: Análisis institucional, Atención de enfermería, Estrategia de Salud Familiar, Gestión de la Salud.

\section{Introdução}

O enfermeiro é caracterizado e reconhecidopor prestar assistência integral identificando necessidades e expectativas, tanto individuais como coletivas, no seu processo de trabalho. Em sua prática é possível reconhecer a articulação dosdiferentes saberes profissionais, dos usuários e da comunidade em busca da otimização das intervenções de cuidado ${ }^{1}$.

Essas intervenções visam possibilitar ao enfermeiro,ter uma visão de valores e lógicas diferenciados impressos nas necessidades dos usuários, implicando em uma reflexão críticasobre os processos de gerenciamento do cuidado.

Em tal contexto, espera-se que esse profissional desenvolva habilidades gerenciais em uma perspectiva participativa, no qual o objetivo é alcançado pelo esforço coletivo e não pela união de esforços individuais².

Percebe-se na Unidade de Saúde da Família que o processo de trabalho do enfermeiro apresenta-se sob duas dimensões complementares principais: cuidado

Afiliação dos autores: 1. Enfermeira.Mestranda do Mestrado Profissional em Ensino na Saúde/MPES. Universidade Federal Fluminense-UFF/Niterói; Brasil.Email:adiceafer@gmail. com ORCID:https://orcid.org/0000-0002-4977-3835

2.Enfermeira. Pós Doutora em Enfermagem. Professora Titular, Programa de Mestrado Profissional em Ensino na Saúde/MPES, UFF, RJ, Brasil. Email:abrahaoana@gmail.com ORCID: https://orcid.org/0000-0002-0820-4329

Email de correspondência: andriacsouza@gmail.com 
e gerência. Na primeira, o enfermeiro toma como objeto de intervenção as necessidades de cuidado de enfermagem e tem por finalidade o cuidado integral e de qualidade; no segundo, o enfermeiro toma como objeto à organização do trabalho e os agentes de enfermagem, visando desenvolver e implementar condições adequadas de cuidado aos usuários e de desempenho para os trabalhadores. Desta forma, o enfermeiro ao exercer a gerência do cuidado na Unidade de Saúde da Família acaba por desenvolver a sua melhor prática e consequentemente a integralidade das suas ações ${ }^{3}$.

O Ministério da Saúde em 2011 aponta como atribuição do enfermeiro "planejar, gerenciar, coordenar, executar e avaliar a Unidade de Saúde da Família", o que traz à discussão os aspectos gerenciais da equipe e da unidade, que não podem ficar limitados às atividades administrativas burocráticas, pondo como função básica apenas o controle do trabalho, mas considerar as dimensões que a atividade gerencial apresenta, principalmente quando se tem as ações em saúde como disparadora da transformação de modelo assistencial ${ }^{4}$.

Objetivos: conhecer o processo de trabalho dos enfermeiros nas Unidades de Saúde da Família; identificar os fatores que intervém na implementação de ações gerenciais voltadas para o cuidado nas Unidades de Saúde da Família.

\section{Método}

Realizar-se-á uma pesquisa de abordagem Socioclínica Institucional modalidadedesenvolvida por Gilles Monceau nos anos 2000, que se apoia na Análise Institucional. Uma proposta composta por diversos saberes e práticas, que teve sua origem em torno dos anos de 1960, na França. No Brasil, o institucionalismo foi introduzido a partir de 1970.

A Análise Institucional,estácentrada em oito pilares: análise da encomenda e demanda; participação dos sujeitos no dispositivo; trabalho dos analisadores; análise das transformações que ocorrem à medida que o trabalho avança; aplicação de modalidades de restituição; trabalho das implicações primárias e secundárias; intenção de produção de conhecimentos e atenção aos contextos; e interferências institucionais.

A Socioclínica Institucionalaproxima-se das questões sociais, com a lógica de transformar para conhecer, em uma produção coletiva do conhecimento e troca de saberes e aprenderes entre participantes e pesquisadores. Um movimento de investigaçãoque não fica limitada a uma lista de princípios ou regras a ser seguidas, e não se faz prisioneira de protocolos rígidos, mas está baseada em características que determinam sua relação com os sujeitos e objetos ${ }^{5}$.

Os participantes do estudo serão profissionais enfermeiros que atuam em Unidades de Saúde da
Famíliade um município localizado na Região Serrana do Estado do Rio de Janeiro, vinculados ao gerenciando do cuidado.

O pesquisador irá apresentar a proposta do estudo Socioclínico Institucional para os participantes da pesquisa.Após declarar a participação na pesquisa os participantes irá assinar o Termo de Consentimento Livre e Esclarecido em duas vias o qual uma do pesquisador e outra do participante.O cenário da pesquisa será Unidades Básicas de Saúde da Família.

Leva-se em consideração o critério de inclusão: enfermeiros que possuem um tempo maior que um ano em exercício nas Unidades de Saúde da Família e critério de exclusão: enfermeiros que estejam de férias, licenças ou afastados.

Os dados coletados nessa pesquisa são descritivos, recolhidos nos encontros socioclínico institucional que retrataelementos existentes na realidade estudada. Haverá para tanto, o emprego do diário de campo e da gravação dos encontros.

A construção do grupo socioclínico, somado aodiário de campo do pesquisador na perspectiva do institucionalismo, consiste em uma ferramenta com o potencial de produzir movimentos de reflexão da própria prática, a partir do momento em que o ato de escrever se torna uma ocasião plausível para reflexão acerca do vivido, revelando os nãos ditos. Além disso, ele explicita a inexistência de neutralidade do pesquisador no ato de pesquisar.

Para análise dos dados será utilizadouma análise de material empírico do grupo, transcrição, transposição e restituição. Na transcrição, a cena observada é passada do testemunho para a sua inscrição na forma de um discurso escrito, acrescentando-senotas de campo e reproduções ${ }^{6}$.

$\mathrm{Na}$ transposição, enquanto as notas de campo são escritas, categorizadas, comentadas ou reescritas, ocorre o momento em que as palavras e os gestos dos atores são reconsiderados e restituídos por meio das palavras do pesquisador?

E na restituição, normalmente constituída pelo relatório final, é o momento em que se ganha uma forma de narrativa que discute em torno das principais categorias de análise e pistas de interpretação ${ }^{8}$.

A proposta de pesquisa foi apresentada ao Programa de Pós-graduação do Mestrado Profissional em Ensino na Saúde Formação Docente Interdisciplinar para o SUS, da Escola de Enfermagem Aurora de Afonso Costa (EEAAC)- Universidade Federal Fluminense (UFF) Campus Niterói,linha de Pesquisa: Educação Permanente no SUS, esse projeto de pesquisa foi submetido ao Comitê de Ética e Pesquisa da Universidade Federal Fluminense obtendo aprovação sob o número CAAE 12129619.3.0000.5243 e parecer 3.333.232 no ano de 2019. 


\section{Resultados Esperados}

Espera-se contribuir com o processo de trabalho dos enfermeiros atuantes nas Unidades de Saúde quanto aocuidado, com intervenções, ações de saúde, resolutividade e tomada de decisões. Os encontros em grupo poderão proporcionar um guia de ferramentas que possibilitem a um "coletivo organizado para a gerência do cuidado nas Unidades de Saúde da Família" ao discutir processo de trabalho através do desenho Socioclínico Institucional, estimulando a criticidade dos pesquisadores e participantes dessa pesquisa para que sejam multiplicadores corresponsáveis dos cuidados individuais e coletivo.

\section{Referências:}

1-Lowen IMV, Peres AM, Crozeta K, Bernardino E, Beck CLC. Competências Gerenciais dos Enfermeiros na Ampliação da Estratégia Saúde da Família. RevEscEnferm USP. 2015; 49(6):967-973.Disponível em: http://www.scielo. br/pdf/reeusp/v49n6/pt 0080-6234-reeusp-49-06-0967.pdf

2- Ludmila Mourão Xavier-Gomes et al. Prática Gerencial do Enfermeiro na Estratégia Saúde da Família. Trab Educ. Saúde, Rio de Janeiro.2015set./ dez;13(3):695-707. Disponível em: http://www.scielo.br/scielo.php?pid=S1 $98177462015000300695 \&$ script $=$ sci abstract\&tlng $=$ pt

3-Fernandes MC, Silva LMS, Moreira TMM, Silva MRF. Fatores intervenientes na Gerência do Cuidado do Enfermeiro: estudo descritivo. Online braz j nurs [Internet]. 2013 Sept [cited year mouth day]; 12 (2): 52233.Disponívelem:http://www.objnursing.uff.br/index.php/nursing/article/ viewFile/4081/pdf_1

4- Ribeiro et al. Gestão em Saúde Pública: Um Enfoque no Papel do Enfermeiro. R brasci Saúde. 19(3):247-252, 2015.Disponível em:http:// www.periodicos.ufpb.br/ojs/index.php/rbcs/article/view/22126

5- L'abbate S, Mourão LC, Pezzato LM. Análise Institucional \& Saúde Coletiva. SP: Hucitec Editora; 2013.

6- Monceau Gilles. A socioclínica institucional para pesquisas em educação e em saúde. L'abbate S, Mourão LC, Pezzato LM, organizadores. Análise institucional e saúde coletiva no Brasil. São Paulo: Hucitec, p. 91-103, 2013. Disponível em:https://www.researchgate.net/publication/305808891_A_ socioclinica institutional para pesquisa em educacao e em saude

7- Paillé P; Mucchielli A. L'analyse qualitative en sciences humaines et sociales-4e éd. Armand Colin, 2016.

8-Silva SO, Silva THF, Almeida SMO, Silva TO. Interpretation and implementation of care technologies in the setting of Primary Health Care. J Nurs UFPE on line.2015;9(12):1174-81.Disponível em:http://www.revista. ufpe.br/revistaenfermagem/index.php/revista/article/view/6910/pdf_ 9055

9- Assis MMA, Nascimento MAA do, Pereira MJB, Cerqueira EM de. Comprehensive health care: dilemmas and challenges in nursing. Rev Bras Enferm. 2015;68(2):333-8.Disponível em:http://www.scielo.br/pdf/reben/ v68n2/en_0 034-7167-reben-68-02-0333.pdf

10- Silva MRF da, Silveira LC, Pontes RJS, Vieira AN. Care beyond health: mapping bonding, autonomy and emotional territory in Family Health. Rev Min Enferm; 2015 Jan/Mar; 19(1):255-259. Disponível em: http://www. revenf.bvs.br/pdf/reme/v19n3/en_v19n3a07.pdf 